\title{
Teaching Significant and Sensitive Issues in the 21st Century-Teaching of Sexual Offenses in the Law Faculty-A Ghanaian Perspective
}

\author{
Kujo E. McDave \\ Pentecost University College, Greater Accra Region, Ghana
}

\begin{abstract}
The Faculty of Law, among others, has the primary purpose of teaching and training law students to be lawyers and advocates of the voiceless. However, recent developments have made teaching of some significant yet sensitive topics, such as abortion rape, defilement, and other sexual offenses very difficult. Some students find the teaching of such topics at the Law Faculty unpleasant. Those affected by the teaching of such topics may either be survivor of a sexual offence or students who for socio-cultural beliefs and principles may also find such topics unpleasant. This has really influenced the teaching of sensitive issues at the various Law Faculties across the globe with Ghana not being an exception. This paper focuses on the conflict between the decisions of the Supreme Court of Ghana where the Court established that for the purpose of justice, words used in sexual offenses must be brutally frank, whiles the social cultural influence position of these topics argues for the use of euphemisms since it is a taboo and considered immoral to identify sexual organs by their names. The paper endeavors to explain why the teaching of these sensitive topics in the 21 st century is quite a challenge. In Ghana, these topics form part of the content of Criminal Law, a mandatory course needed for pursuing professional legal studies. For this reason, it is not a question of whether or not it should be taught in the Law Faculty but how it should be taught. The paper proposes values and means that can be essential, and when applied to the teaching of rape and sexual offenses, it will mitigate and address the unpleasant nature of the topics and rather encourage the students to participate in the teaching and discussion of these topics. It concludes by outlining the need for student lawyers having the knowledge in these topics and its impact on society.
\end{abstract}

Keywords: education, law, legal profession, sexual offenses, sensitive issues, significant courses, teaching strategy and techniques, justice, training law students

Indeed there are many areas of the law and its experience has shown that both students and teachers find them quite challenging to discuss because they are considered to be very sensitive; and yet very significant. This paper will focus on sexual offences.

"In offenses like rape, defilement and indeed in respect of any of the sexual offenses, use of language must be brutally frank in order to depict and establish the essential ingredients of the offense charge" (Banousin v The Republic [2015], G.N.L.C.L.R 439 S.C.).

Kujo E. McDave, associate dean, Faculty of Law, Pentecost University College, Greater Accra Region, Ghana. 
There have been several occasions where students during the semester and in their post semester assessments have suggested that the Criminal Law class is discomforting for various reasons. Among these complainants are students who have been victims of sexual assault and are not comfortable reliving such experience. The other category of students is those who for cultural, socio-cultural, religious, or personal principles, orientation, upbringing, and other societal norms are not comfortable with the content of the course.

\section{Culture, an Influence on Teaching of Sexual Offenses in Law Faculty}

Globally, there is an accepted phenomenon which is the fact that a person's way of life could be influenced by the culture they are associated with. For example, in some parts of the Western world, it is permissible to greet with the left hand whiles such an act is seen as a taboo in other places, i.e., Ghana. Culture is inherent in the Ghanaian society to the extent that it is an integral part of the socialization process where the family and the school have a responsibility of passing on to the younger generation norms and values of the society. For this reason, culture has permeated through all forms of education in Ghana be it formal or informal education. Culture which in simple terms means a way of life plays a significant role in the educational system.

Sexual offenses may include incest, rape, sexual assault, defilement, and so on; depending on the jurisdiction, one may find himself or herself.

In Ghana, cultural taboos and some norms do not easily allow for a straight forward and a direct education of adolescents on sexuality. Among the Akans ${ }^{1}$, for instance, it is a taboo to talk about sexual issues with a child because they believe that the child could be "spoilt" by that. Even if the child wants to find out certain things about sex, the elders will tell the child that he/she is not matured enough to know about such issues. Due to the taboos associated with sexuality, some parts of the body could not be mentioned because it was considered a taboo to do so. For that matter, they express such things using euphemisms and other symbolic terms and language. For example, they prefer to call the penis "manhood and the vagina womanhood (Baku, Adanu, \& Adatara, 2017). Traditionally, discussion about sexuality is subdued and subsumed in proverbs due to the sensitivity attached to it.

However, the legal position in Ghana speaks otherwise. In the case of Banousin v the Republic, the Supreme Court of Ghana in their ruling established that in matters of sexual offenses, words, and expression used should be brutally frank. Where appropriate words are not used in sexual offenses, injustice is likely to be caused.

Again, in Hanson $v$ The Republic (1978) GLR447, the Court held that the prosecution must prove that the man had sexual intercourse with the woman. Sexual intercourse means that the man should have used his penis to penetrate the woman's vagina.

This position of the Court implies that in teaching of sexual offenses in a Law Faculty in Ghana, words used must not be euphemistic but must be clearly said, stated, and called by their names as such.

Flowing from the above, there is an indication of conflicting ideologies when it comes to teaching of issues of sexual offenses in Ghana. Whiles the society believes that such issues are sensitive and must be expressed with the used of proverbs and euphemism, the Court provides that words should be mentioned as it is.

\footnotetext{
${ }^{1}$ Akan is the name of the largest tribe in Ghana.
} 
Admittedly, the teaching of sexual offenses is significant and yet sensitive, and its sensitivity is dependent on who is affected. So, the question is who are those affected?

The first is victims of sexual abuse, such as rape. Students who have been victims of sexual abuse express how discomforting it is to be in class when such topics are being taught.

The second is the society including at times some teachers. Within a law class, they are a representation of a certain class of people who owing to religious or cultural or upbringing or personal principles (societal norms) do not want such topics to be taught. They find the teaching of sexual offenses and the position of the Court on the choice of words to be used as alien to the Ghanaian society.

It is clearly established that victims of sexual assault go through long periods of therapy to overcome such repugnant memories and its effect by consciously pushing such memories into the subconscious state.

For this reason, the teaching of such a significant and yet sensitive area of law becomes problematic for students who have been victims of sexual offenses as it does not only remind them what they have experienced but also a replay and relive of such events.

This phenomenon or concept which has been described by renowned psychologists Lee Madigan and Nancy Gamble as the second rape is devastating and despoiling than the first thus to say more cruel and traumatic than the act itself.

Rebecca Campbell, a professor of Community Psychology and a Program Evaluation at Michigan State University, said the process of seeking help after sexual assault with regards to medical exam, and reporting to the police the steps of prosecution is very traumatizing and was re-traumatizing. It feels like a second rape, "I feel like the rape just keep going". Such is the ordeal of law students who are victims of rape and sexual assault and have to read and learn about rape.

Professor Jeannie Suk Gersen, in her article "The Trouble with Teaching Rape Law December 15, 2014", stated that about a dozen new teachers of Criminal Law at multiple institutions have shown that they are not including rape law in their courses, arguing that it is not worth the risk of complaints of discomfort by students. Even seasoned teachers of Criminal Law, at law schools across the country, have confided that they are seriously considering dropping rape law and other topics related to sex and gender violence. So, the question is how do we fight the menace of sexual offenses if we do not train and acquire expertise for it?

With the growing concerns about the teaching of sexual offenses in the Law Faculty, should it be taught?

Law schools have long focused on training students how to think like a lawyer. This translates into designing a curriculum which will prepare the student to meet the realities and challenges of the legal world. Law students are taught a wide range of courses which includes Administrative Law, Land Law, Constitutional Law, Criminal Law, Legal Research, Jurisprudence, and Advocacy just to mention a few.

The significance of the content of each of the courses taught in law schools cannot be over emphasized. A large part of lawyering means getting involved in the personal, private, business, and sensitive happenings in the lives of clients.

What makes lawyering a calling and a profession is how we serve as voice for the voiceless. Advocacy is a basic attribute of a lawyer. Being an advocate exposes a lawyer to extremely significant and sensitive issues, such as sexual offenses, murder, issues of sexual orientation, abortions, and violations of human rights.

Clearly, it becomes quite a challenge for a teacher in any field of teaching, to teach a course which his or her students are afraid to study. 


\section{Techniques to Aid in Teaching Sensitive Topics (Rape)}

The significance and the need to teach sexual offenses, such as rape as part of a Criminal Law class cannot be overemphasized. As earlier on established, in Ghana, it is a mandatory course and a requirement before a student can sit for the entrance examination into the Professional Law School. For this reason and for the relevance of this significant yet sensitive topic, students cannot be shielded from the topic by avoiding the topic but rather there should be efforts to mitigate any potential unpleasant effect. Measures to be put in place to enhance teaching of sensitive topics should include but not limited to orientation and the use triggering and symbolic words.

\section{Orientation}

Prior to the commencement of the course, students are given a detailed course outline of the course and the respective topics. A seminar could be held to introduce the content of the course outline and allow students to ask questions. This allows the lecturer to address any misunderstandings or wrongful perceptions.

This exercise will allow students to appreciate the composition of the course and prepare themselves physically and most importantly mentally and psychologically for the course. This should part of efforts by the lecturer to aid the student to adjust to the sensitive nature of the topic. A good orientation will prepare students well for the topics; however, it may not be enough to address the overall unpleasant effects of the sensitive nature of the topic.

The lecturer, on the other hand, will be pointed to other directions and view points and the orientation of the class for him /her to prepare adequately. Such interaction is likely to be of immense significance to both the lecturer and the student.

\section{The Orientation Proposes the Adoption of Some Values in Teaching Significant and Sensitive Topics Such As Rape}

The teaching of significant and sensitive issues (sexual offenses), such as rape requires a well-structured content with regards to the values of teaching and the values of the society and the community. The high incidence and prevalence of sexual offenses indicate that there is the probability of a number of classes having a survivor of a sexual assault. Teaching of significant and sensitive issues can be very challenging; however, a combination of the knowledge or content of the topic and values needed to teach and its overall value to the society and the community could serve as a guide as to what and how to teach.

Lecturers are pivotal in the teaching of significant and sensitive topics as they are in a position of trust. Students appreciate information flowing from their lecturers. Beyond having control over the subject area, lecturers are expected to identify how students react to such significant and sensitive topics and manage the reactions accordingly.

These values are essential as they allow the lecturer to engage the students in a less tensed and anxious environment, where students can openly express their views yet fall within the objectives of the course. We will attempt to look at some of these values which include respect, fairness, firmness, objectivity, and tolerance just to mention a few.

\section{Respect}

In as much as teaching of sexual offenses are sensitive and as earlier indicated above, the Ghanaian courts 
encourage lecturers and all stakeholders to be brutally frank in matters regarding sexual offenses; there should be mutual respect on the part of the lecturers towards the students and vice versa, and among students. Lecturers of such courses must respect the sensitivity of the receivers or people who are affected by hearing sex related topics. Lecturers must not overlook the reactions of individuals and how such messages are welcomed by students. Facial expressions of students, body gestures, and verbal reactions must be taken into consideration by lecturers. Regardless of the value and how trivial an expression may be, lecturers must appreciate the concerns and input of students.

\section{Fairness}

Fairness generally means every individual has the same opportunities and is subject to the same limitations. According to Lexico Dictionary, it is an impartial and just treatment or behavior without favoritism or discrimination. Lecturers must be fair to the students by giving them the necessary platform to express their concerns. To ensure the class is engaging and effective, students with diverse views must be permitted to express themselves with regards to the topic. It is very key that a wrong impression is not created to suggest that certain views are superior to others.

\section{Firmness}

Due to the sensitive nature of the topic, lecturers are encouraged to have a more engaging class to allow for a conducive and less anxious environment. However, firmness is of utmost importance. Lecturers are to ensure that in creating such environment, students are not mocked or intimidated based on their views which may flow from their cultural or religious beliefs or for being a survivor of sexual assault.

\section{Objectivity}

Lecturers must have an open mind and ensure that explanation of the principles underlining the concept of sexual offenses (rape) is made independently and devoid of sentiments and personal bias. Such biases may be as a result of the lecturers' gender, sexual orientation, religion, culture, or personal experience. Lecturers must be able to detach their persons from the teaching of sexual offenses. For instance, a lecturer who aligns herself as a feminist must teach sexual offenses devoid of her allegiance and appreciate the diversity of opinions but ultimately getting the principles of the topic across to the students, for students to appreciate and make their own informed decisions.

\section{Tolerance}

The educational system has become more multi-cultural and multi-religious. This means a classroom is likely to comprise of students of different cultural, religious, political, and social orientation. The lecturer also will have a distinct orientation from some of the students. The key to a harmonious class where topics are significant and yet are as sensitive as rape and sexual offenses can be taught is through tolerance, hence the need for mutual respect and appreciation of each other's orientation and thought process. Topics such as rape cannot be effectively discussed without appreciating the diverse opinions and comprehension of the various group affected by its sensitive nature.

\section{The Use of Triggering/Symbolic Words}

This basically is a word or phrase warning others of a potential distressing or unpleasant material or content. The teaching of sexual offences includes making graphical references and the use of words that could be provocative. Victims or survivors of sexual assault and persons who for their religious or cultural beliefs, 
object to the teaching and use of particular language because it may be traumatic or emotionally injurious or immoral, will appreciate the effort being made to mitigate their concerns with the use of these trigger or symbolic words or phrases.

\section{Conclusion}

In the era of increased incidence of sexual violence, such as rape, the teaching of sexual offenses in a Criminal Law class is of utmost importance than ever. The only lawful medium to ensure that perpetrators of sexual offenses are deservedly punished is by the courts. This translates to the need for competent and well trained lawyers as the advocates for victims of sexual offenses. In the author's opinion, the teaching of sexual offenses, though sensitive is very significant, must therefore be done well to ensure justice.

Students will have to dispassionately evaluate their beliefs and values in relation to principles taught by their lecturers as this will enable them appreciate the significance of these principles in administering justice. If the laws to protect the citizenry cannot be taught and learned by the very people who have the responsibility of ensuring justice, then the society will be unsafe.

The benefits of justice are well established, which include serving as a deterrence to others who may have similar thoughts of committing same or similar offense. It is to incapacitate the perpetrators from inflicting such physical and psychological burden on their victims and with the hope of transforming such offenders through rehabilitation. Again justice, when seen as done gives the victims a sense of relief, knowing the offender has been punished appropriately.

To sum it up, cultural and religious reasons make the teaching of sexual offenses sensitive and unpleasant to some law students and others; however, its significance is definitely not in doubt. Its purpose is to protect citizens and make the community safer.

\section{References}

Baku, E., Adanu, R., \& Adatara, P. (2017). Socio-cultural factors affecting parent-adolescent communication on sexuality in the Accra Metropolis, Ghana. Numid Horizon, International Journal of Nursing and Midwifery, 1(2), 1-10. 